\title{
Determination of body composition from skinfold thickness: a validation study
}

\author{
J J Reilly, J Wilson, J V G A Durnin
}

\begin{abstract}
Measurement of body composition is proving increasingly important in clinical nutrition and research. Skinfold thickness is a simple means of estimating body composition which is widely used in children, but there is little information on its validity. There has been a proliferation of equations for estimation of body composition from skinfolds, but some doubt as to their general applicability. The aim of the present study was to validate five currently used equations for this purpose in a sample of 98 healthy prepubertal children (64 boys, 34 girls), mean (SD) age 9.1 (1.7) years by comparison of estimates from each equation with measurements of fatness derived from hydrodensitometry. Differences between methods were determined by calculation of biases and limits of agreement. Limits of agreement between predicted and measured fatness were wide, particularly in the girls, and some distinct biases were apparent. Choice of prediction equation therefore has a substantial influence on the estimate of fatness obtained when using skinfolds in children. The existing published equations are associated with large random errors or significant systematic errors. For the time being skinfolds might best be regarded as indices (rather than measures) of body fatness in individuals, or means of estimating body fatness of groups. Estimating the total body fatness of individual prepubertal children using skinfolds, on the basis of this evidence, is not advisable at present.

(Arch Dis Child 1995; 73: 305-310)
\end{abstract}

Keywords: body fatness, fat free mass, validation, nutritional status.

A recent editorial in this journal noted the inability of classical measures of growth and development to meet the requirements of modern clinical medicine and research', and suggested that measurement of body composition could meet these requirements. ${ }^{1}$ There has been a resurgence of interest in body composition in childhood as a result of increased awareness of its importance ${ }^{12}$ and the proliferation of new measurement techniques.

Measuring the body composition of children is problematic for practical and theoretical reasons. Many standard methods of assessment (for example, hydrodensitometry) can be impractical, particularly in young or disabled children. Theoretical problems arise largely from the 'chemical immaturity' of children. Assumptions of constant composition of fat free mass (FFM), made routinely in adults, are invalid in children ${ }^{23}$ and approaches that take account of the changing composition of FFM with advancing age ${ }^{24}$ are therefore necessary.

There is a need for simple 'bedside' methods of body composition measurement which have been validated and are generally applicable in children. ${ }^{5}$ In adults skinfold thickness has been shown to be as valid as any other method for the measurement of absolute fat mass and FFM, ${ }^{6}$ and changes in fat mass and FFM, ${ }^{7}$ even in populations where the composition of FFM is particularly variable. ${ }^{8}$

Measurement of skinfold thickness is currently widely used in children for clinical, research and epidemiological purposes, but there are doubts about its validity in infancy, 89 no empirical demonstrations of its validity in prepubertal children, and concerns over age related variability in the composition of FFM, ${ }^{2}$ and variability in skinfold compressibility, ${ }^{10}$ both of which have a bearing on the validity of the technique. Furthermore, many equations exist for the estimation of body fatness from skinfold thickness in children. There is evidence that some skinfold equations are highly population specific ${ }^{11} 12$ but also reports that some equations are considerably less so $^{13}$ and so are generally applicable. In summary, the user of skinfold thickness in childhood is therefore faced with a choice of equations for estimating fatness, but these may not be applicable to the population under study. More fundamentally, the technique itself is of unknown validity in the prepubertal child. The aims of the present study were to cross validate the more commonly used equations for prediction of body fatness from skinfold thickness in healthy prepubertal children, and to describe biases and errors in estimation by comparison with fatness measured using hydrodensitometry, the reference method. The precision of the skinfold technique was also assessed.

\section{Subjects and methods}

SUBJECTS

The study sample consisted of 98 healthy, self selected children; there were 64 boys (mean (SD) age $9.3(1.7)$ years) and 34 girls (9.0 $(1 \cdot 7)$ years). Subjects were recruited from local schools and informed consent was obtained from parents. Ethical approval was obtained from the Yorkhill Hospitals ethics committee. Physical characteristics of subjects are described in table 1 . Body fatness (\% of body weight, $\mathrm{BF} \%$ ) ranged from 4.0 to $39.1 \%$ in boys and from $4 \cdot 1$ to $32 \cdot 8 \%$ in girls with the 
Table 1 Characteristics of subjects

\begin{tabular}{|c|c|c|c|c|c|c|}
\hline & \multicolumn{3}{|c|}{ Boys } & \multicolumn{3}{|c|}{ Girls } \\
\hline & No & Mean (SD) & Range & No & Mean (SD) & Range \\
\hline $\begin{array}{l}\text { Age (years) } \\
\text { Weight }(\mathrm{kg}) \\
\text { Height }(\mathrm{m}) \\
\text { Density }(\mathrm{kg} /)^{\star} \\
\text { BF\%॰ }\end{array}$ & $\begin{array}{l}64 \\
64 \\
64 \\
57 \\
57\end{array}$ & $\begin{array}{c}9 \cdot 3(1 \cdot 7) \\
32 \cdot 0(8 \cdot 6) \\
1.36(0 \cdot 10) \\
1.055(0.016) \\
13 \cdot 2(8 \cdot 0)\end{array}$ & $\begin{array}{c}5 \cdot 8-11 \cdot 7 \\
20 \cdot 3-59 \cdot 2 \\
1 \cdot 18-1 \cdot 57 \\
1 \cdot 003-1 \cdot 077 \\
4 \cdot 0-39 \cdot 1\end{array}$ & $\begin{array}{l}34 \\
34 \\
34 \\
24 \\
24\end{array}$ & $\begin{array}{c}9.0(1 \cdot 7) \\
31.0(7 \cdot 6) \\
1.33(0 \cdot 11) \\
1.037(0.016) \\
19 \cdot 8(7 \cdot 9)\end{array}$ & $\begin{array}{c}6 \cdot 3-11 \cdot 3 \\
21 \cdot 9-50 \cdot 1 \\
1 \cdot 15-1 \cdot 59 \\
1 \cdot 012-1 \cdot 068 \\
4 \cdot 1-32 \cdot 8\end{array}$ \\
\hline
\end{tabular}

$\star$ Density, and density derived estimates of fatness, available for 57/64 boys and 24/34 girls.

reference method, indicating heterogeneity of the sample with respect to fatness.

\section{ANTHROPOMETRY}

Body weight was measured to $0 \cdot 1 \mathrm{~kg}$ using a standard beam balance. Height was measured to $0.5 \mathrm{~cm}$ using a Holtain wall mounted stadiometer. In all subjects four skinfold thicknesses (biceps, triceps, subscapular, suprailiac) were measured (as previously described ${ }^{14}$ ) in triplicate, by the same trained observer. Measurements were made on the right hand side of the body using a Holtain caliper. In 17 subjects all anthropometric procedures were repeated within seven days of the initial visit. The test-retest data were then used to calculate the precision of skinfold thickness measurement.

\section{MEASUREMENT OF BODY DENSITY}

In 57 boys and 24 girls body density was measured in triplicate, using hydrodensitometry. Residual volume determination was made by nitrogen wash out, as previously described. ${ }^{14}$ Seven of the 64 boys and 10 of the 34 girls were unable or unwilling to undertake the underwater weighing procedure.

\section{CONVERSION OF MEASURED OR PREDICTED} DENSITY TO BODY FATNESS

In all children measured or predicted density was converted to an estimate of $\mathrm{BF} \%$ using a modification of the $\mathrm{Siri}^{15}$ equation proposed by Westrate and Deurenberg:

$$
\mathrm{BF} \%=[562-4 \cdot 2(\text { age }-2)] / \mathrm{d}-[525-4 \cdot 7(\text { age }-2)]
$$

where age is in years, $d=$ density $(\mathrm{kg} / \mathrm{l})$. Use of the $\mathrm{Siri}^{15}$ equation in children, with its inherent assumption of FFM density of $1 \cdot 1 \mathrm{~kg} / \mathrm{l}$, leads to systematic overestimation of body fatness from density. Two alternative models have been constructed, ${ }^{24}$ based on empirical data, which are unbiased and more physiological, assuming increasing FFM density during childhood. These models predict similar fatness at the same density and the equation of Westrate and Deurenberg ${ }^{4}$ was chosen for convenience.

\section{PREDICATION OF BODY DENSITY OR FATNESS} FROM PUBLISHED EQUATIONS: VALIDATION STUDY

Five empirically derived equations for the prediction of density or $\mathrm{BF} \%$ from skinfolds were tested.
(1) Equations of Durnin and Rahaman ${ }^{16}$

Predicted density (kg/l):

Boys $=1 \cdot 1533-0.0643 \times(\log$ sum of 4 skinfolds $)$

Girls $=1 \cdot 1369-0.0598 \times(\log$ sum of 4 skinfolds $)$

These equations were derived from empirical relationships between skinfold thickness and body density in adolescents ( 48 boys age range $12 \cdot 7-15 \cdot 7$ years; 38 girls age range $13 \cdot 2-16 \cdot 4$ years). Their validity in younger children was unknown, and as the methodology used was identical to that in the present study, a test of cross validation was justified.

(2) Equations of Slaughter et al ${ }^{17}$

$\mathrm{BF} \%$ for children with triceps and subscapular skinfolds $<35 \mathrm{~mm}$ :

Boys $=1.21$ (sum of 2 skinfolds) -0.008 (sum of 2 skinfolds 2$)-1.7$ Girls $=1.33$ (sum of 2 skinfolds) -0.013 (sum of 2 skinfolds $\left.{ }^{2}\right)-2.5$

$\mathrm{BF} \%$ for children with triceps and subscapular skinfolds $>35 \mathrm{~mm}$ :

Boys $=0.783$ (sum of 2 skinfolds) $-1 \cdot 7$

Girls $=0.546$ (sum of 2 skinfolds) +9.7

These equations are based on an empirically derived multicomponent method utilising measurement of body density, total body water, and bone mineral content of radius and ulna. The sample used to derive these particular equations consisted of 50 boys (mean age 9.8 years) and 16 girls (mean age 10.0 years) from the USA. The cross validity of the Slaughter et al equations has been reported to be high, ${ }^{13}$ and these are effectively the 'standard' equations used in North America.

(3) Equations of fohnston et al ${ }^{18}$ Predicted density $(\mathrm{kg} / \mathrm{l})$ :

Boys $=1 \cdot 1660-0 \cdot 0070 \times(\log$ sum of 4 skinfolds $)$ Girls $=1 \cdot 144-0.060 \times(\log$ sum of 4 skinfolds $)$

These equations are based on empirically derived relations between skinfolds and density of Canadian children aged 8-14 years (140 boys, 168 girls). The cross validity of these equations has not been reported.

\section{(4) Equations of Brook $k^{19}$}

Predicted density $(\mathrm{kg} / \mathrm{l})$ :

Boys $=1 \cdot 1690-0.0788 \times(\log$ sum of 4 skinfolds $)$ Girls $=1.2063-0.0999 \times(\log$ sum of 4 skinfolds $)$

These equations were derived from empirical relations between total body water and body density (predicted from equations for adolescents ${ }^{16}$ ), in a sample of 13 obese children and 10 with short stature, age range 1-11 years. The equations are widely used in the UK.

(5) Equations of Deurenberg et $\mathrm{al}^{20}$

Predicted density (kg/l) (prepubertal):

Boys $=1.1133-0.0561 \times(\log$ sum of 4 skinfolds $)+1.7\left(\right.$ age $\left.\times 10^{-3}\right)$ Girls $=1.1187-0.063 \times(\log$ sum of 4 skinfolds $)+1.9\left(\right.$ age $\left.\times 10^{-3}\right)$

These equations are based on empirically derived. relationships between skinfolds and density in Dutch children (114 boys mean age 11.0 years; 98 girls mean age 10.5 years). The equations are now widely used, but their cross validity has not been reported. 
Table 2 Group mean (SD) estimates of $B F \%$ by five equations and densitometry in girls and boys

\begin{tabular}{lll}
\hline & Boys $(n=57)$ & Girls $(n=24)$ \\
\hline Densitometry & $13 \cdot 2(8 \cdot 0)$ & $19 \cdot 8(7 \cdot 9)$ \\
Equations & & \\
(1) Durnin and Rahaman & $10 \cdot 4(6 \cdot 1)$ & $16 \cdot 6(4 \cdot 5)$ \\
(2) Slaughter et al & $15 \cdot 5(5 \cdot 5)$ & $19 \cdot 9(4 \cdot 9)$ \\
(3) Johnston et al & $8 \cdot 2(6 \cdot 5)$ & $13 \cdot 1(4 \cdot 4)$ \\
(4) Brook & $13 \cdot 1(7 \cdot 1)$ & $13 \cdot 3(7 \cdot 3)$ \\
(5) Deurenberg et al & $16 \cdot 2(4 \cdot 9)$ & $19 \cdot 3(4 \cdot 9)$ \\
\hline
\end{tabular}

\section{STATISTICAL ANALYSIS}

Agreement in estimates of $\mathrm{BF} \%$ between the various methods, and agreement between the various methods and hydrodensitometry (selected as the reference method), was determined by calculation of biases, and limits of agreement (bias \pm 2SD) following the method of Bland and Altman. ${ }^{21}$ This focuses on the individual differences between methods and summarises agreement on the basis of how wide or narrow are the limits of the differences between methods. ${ }^{21}$ Group mean estimates by the various methods are also presented. Sample size for comparison between the five equations and densitometry was 57 boys and 24 girls; for comparison between the five equations sample size was 64 boys and 34 girls.

\section{Results}

MEASUREMENT RELIABILITY

For the 17 children included in the assessment of reliability, the mean (SD) of the sum of two skinfolds (triceps plus subscapular) was 13.8 (3.2) $\mathrm{mm}$, and mean of the sum of four skinfolds was $25 \cdot 0(6 \cdot 2) \mathrm{mm}$.

The mean (SD) difference between measurements 1 and 2 for two skinfolds was $0.5(0.8) \mathrm{mm}$ (range -0.8 to $1.8 \mathrm{~mm}$ ), with
$95 \%$ confidence interval (CI) for the difference -0.2 to $0.8 \mathrm{~mm}$. For four skinfolds mean (SD) difference between measurements was 0.8 $(1 \cdot 4) \mathrm{mm}$ (range $-2 \cdot 6$ to $2 \cdot 7 \mathrm{~mm}$ ), with $95 \%$ CI for the difference $-0 \cdot 1$ to $1 \cdot 2 \mathrm{~mm}$. The distribution of differences was normal.

The value mean $\pm(2 S D)$ for differences were used to propagate errors in estimated $\mathrm{BF} \%$ for two and four skinfolds. For two skinfolds this represented maximum differences of $1.8 \mathrm{BF} \%$. For four skinfolds the maximum difference in $\mathrm{BF} \%$ estimates was $1.5 \mathrm{BF} \%$. These differences were similar to those reported for adults. $^{7}$

DIFFERENCES BETWEEN EQUATIONS TESTED AND DENSITOMETRY: BOYS

Some distinct biases were apparent, and limits of agreement (mean $\pm 2 S D$ of differences) between all five equations and the reference method were wide, indicating poor agreement between predictions. ${ }^{21}$ Body fatness was overestimated by the equations of Slaughter et al and Deurenberg et al. The equation of Brook had the smallest bias and narrowest limits of agreements relative to densitometry (table 2). The equations of Durnin and Rahaman and Johnston et al underestimated fatness relative to densitometry, and the latter equation predicted a number of very low fatness estimates (some negative estimates). Limits of agreement between the various equations and each other were generally narrower (that is agreement better) than those between the various methods and densitometry. As an example of the range of estimates which were obtained from the five prediction equations in the same child, in a typical boy predicted fatness ranged from $5 \cdot 3 \%$ (Johnston equation) to
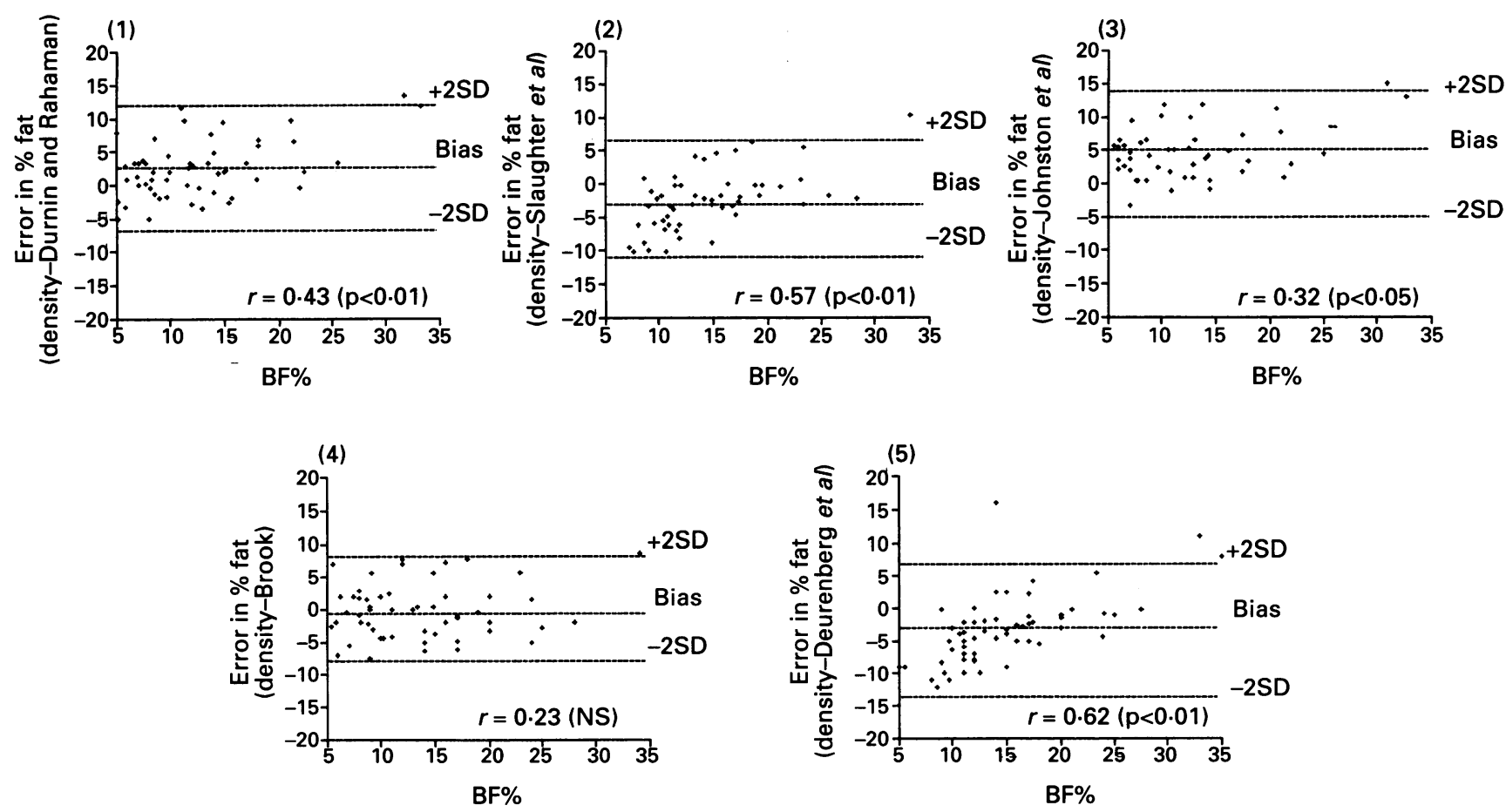

Figure 1 Biases (reference method minus prediction) in BF\% estimates in relation to body fatness in 57 boys; (1)-(5) refer to equations in subjects and methods. 

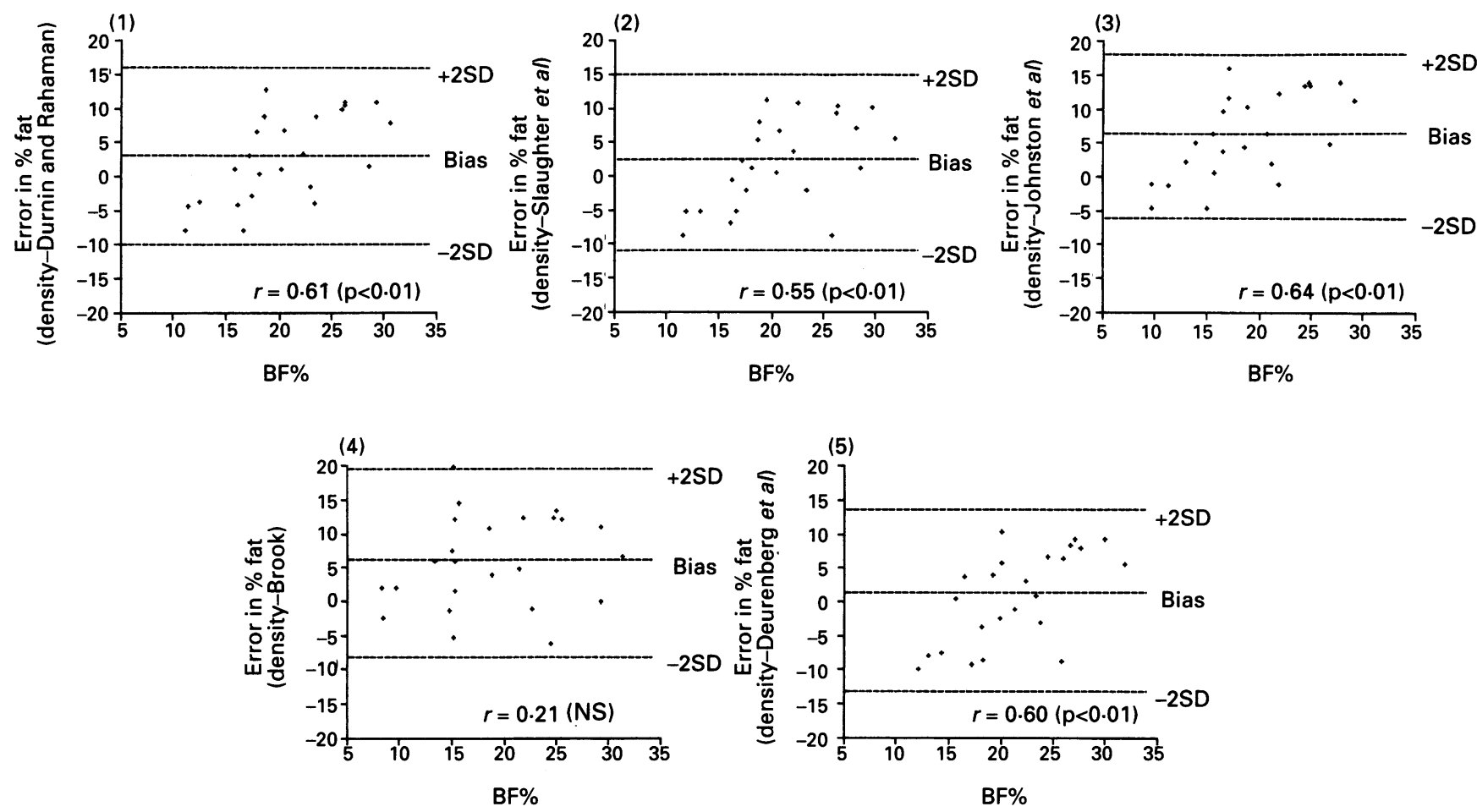

Figure 2 Biases (reference method minus prediction) in BF\% estimates in relation to body fatness in 24 girls; (1)-(5) refer to equations in subjects and methods.

$13 \cdot 8 \%$ (Deurenberg equation) with fatness from densitometry $11.9 \%$.

The relationships with age and body fatness were tested using correlation of the bias observed with fatness derived from the mean of two methods. ${ }^{21}$ In general, there was little evidence of influence of age on the biases observed, but fatness had a significant influence (fig 1) for all the equations tested other than that of Brook, where there was a trend which was not statistically significant.

DIFFERENCES BETWEEN EQUATIONS TESTED AND DENSITOMETRY: GIRLS

Some distinct biases were apparent and limits of agreement between the five equations and densitometry were wider than those in the boys. Estimates of $\mathrm{BF} \%$ between the equations were in closer agreement than those between the equations and densitometry. Highest estimates of $\mathrm{BF} \%$ were produced by the equations of Slaughter et al, followed by (in descending order) those of Deurenberg et al, Durnin and Rahaman, then Brook and Johnston et al (table 2). As in the boys, estimates from each equation in individuals produced widely different values for $\mathrm{BF} \%$. In one typical girl, for example, $\mathrm{BF} \%$ estimates ranged from $10 \%$ (Brook equation) to $19 \cdot 8 \%$ (Deurenberg equation) with true body fatness (densitometry) $17 \cdot 4 \%$.

In the girls there was no evidence that biases in estimation of $\mathrm{BF} \%$ relative to densitometry were age-related except for that of Deurenberg et al (bias and age positively correlated, $r=0.42, \mathrm{p}<0.05)$. There was evidence of an influence of fatness on the magnitude and direction of bias (fig 2) for all equations tested with the exception of that of Brook where, as in the boys, there was a trend which was not statistically significant.

\section{Discussion}

The present study confirms that, for the individual child, there is poor agreement between reference estimates of body fatness and predictions based on measurements of skinfolds. While some of the difference between skinfold methods and densitometry is attributable to variability in the composition of the FFM, and hence to 'error' in the reference method, 215 the study nevertheless suggests that considerable caution should be exercised in predicting body fatness from skinfolds in children, and that the validity of published predictive equations cannot be taken for granted. Poor cross validity has been described for other anthropometric equations in children, 1112 but was not previously established for the equations tested in the present study. Furthermore, more casual users of anthropometric methods are largely unaware of this problem and the methods are widely used with no reference to the validity of the method in particular population groups. The study demonstrates that lack of validity in healthy children is a serious problem and this is likely to be compounded when the methods are applied to patient populations. Alterations in fat distribution ${ }^{22}$ or systematic differences in the composition of FFM associated with disease, ${ }^{23}$ are likely to exacerbate lack of cross validity and lead to poorer prediction. ${ }^{18}$ Users of skinfolds in childhood must consider whether the equations available are valid in their particular group. For many clinical settings equations will be invalid, and they also appear to be invalid in healthy 
prepubertal children on the basis of the present evidence.

The reasons for the poor validity (and lack of general applicability) of the equations tested must lie in methodological or biological differences between studies. The most obvious biological difference between the sample recruited and those recruited in the other studies is age: the equations of Durnin and Rahaman ${ }^{16}$ were based on adolescents and so the evidence of systematic errors in prediction (table 2) are perhaps not surprising. The samples used to derive the Deurenberg et al, ${ }^{20}$ Slaughter et al, ${ }^{17}$ and Johnston et al ${ }^{18}$ predictive equations included some children as young as 7 years, but the age distribution of the present sample was generally younger than in that of these published studies. Since age or maturational state has been identified as an important predictive variable ${ }^{171924}$ this may account for some of the differences observed.

Differences in body fatness between the present sample and those used to derive the various equations may also have contributed to the lack of validity, particularly in view of the evidence that bias was related to the body fatness of the child (figs 1 and 2). This finding has relevance for those wishing to choose equations for particular groups: users of skinfolds should be aware that magnitude and direction or error for some prediction equations will depend on the body fatness of the children being studied. It may be significant that the prepubertal boys recruited by Deurenberg et $a l^{20}$ were fatter than those in the present study, and the boys (mean $23.5 \%$ fat) and girls (mean $27.5 \%$ fat) recruited by Slaughter et al ${ }^{17}$ were considerably fatter than those recruited to the present study.

There were methodological differences between the present study and those used to derive the predictive equations tested. In the present study, and most others, skinfolds were measured on the right hand side, but this was not the case for the equations of Deurenberg et $a l^{20}$ (left hand side). In the present study residual lung volume could not be measured simultaneously with density measurements in situ because most children could not comply with the rebreathing required on surfacing after immersion. This procedure was common to some ${ }^{17} 18$ but not all ${ }^{1620}$ other studies. The different approaches may have introduced systematic differences between methods.

While considerations of body composition of individual children are often of prime importance this is not always the case. Attention has recently been drawn to the lack of validated methods for quantification of body fatness in children in epidemiology, in order to quantify prevalence of obesity for example. ${ }^{25}$ In such circumstances, absence of systematic differences (biases) may be the prime concern and the evidence of poor agreement for individuals may be of secondary importance. The present study suggests that, for groups, the equations of Deurenberg et al and Slaughter et al predicted fatness with negligible bias in the girls and the equation of Brook predicted fatness with negligible bias in the boys (table
2). Measurement of single or multiple skinfolds may also be of value as relative indices of fatness, and may be more appropriately used as indices rather than measures of body fatness of individual children.

In conclusion, the results indicate that prediction of body fatness by measurement of skinfold thickness in prepubertal children is associated with large errors at the individual level. The prediction equation chosen can have a profound effect on the estimate obtained, and care is required in deciding which equation to use. The simplicity of skinfold thickness is attractive and, as the method can be reasonably precise, improvements could be made in the methodology. These are likely to require derivation of predictive relationships on large heterogenous samples of children with external cross validation. Until this has been done, choice of prediction equation will continue to be the major influence on skinfold estimates of fatness in childhood, and the method would seem unsuitable as a means of accurately estimating body fatness of individual prepubertal children.

We thank the volunteers and their families for their cooperation. The Institute of Physiology University of Glasgow provided The Institute of Physiology University of Glasgow provided access to laboratory facilities, Lawrence Weaver commented on an earlier draft of the manuscript. The Department of Human Nutrition is supported by the Rank Prize Funds and Rank
Foundation. The study was funded by the Scottish Office Foundation. The study was
Home and Health Department.

1 Davies PSW. Body composition assessment. Arch Dis Child 1994; 69: 337-8.

2 Lohman TG. Advances in body composition assessment. Monograph No 3. Champaign, Illinois: Human Kinetics Monograph No
Publishers, 1993.

3 Hewitt MJ, Going SB, Williams DP, Lohman TG. Hydration of the fat-free body in children and adults: implications for body composition assessment. $A m \mathfrak{J}$ Physiol 1993; 265: E88-95.

4 Westrate JA, Deurenberg P. Body composition in children. Am f Clin Nutr 1989; 50: 1104-15.

5 Elia M. Body composition analysis: an evaluation of two component models, multicomponent models, and bedside techniques. Clinical Nutrition 1992; 11: 114-28.

6 Fuller NJ, Jebb SA, Laskey MA, Coward WA, Elia M. A four component model for the assessment of body composition in humans. Clin Sci 1992; 82: 687-93.

7 Jebb SA, Murgatroyd PR, Coward WA, Goldberg GR, Prentice AM. In vivo measurement of changes in body Prentice AM. In vivo measurement of changes

8 Reilly JJ, Murray LA, Wilson J, Durnin JVGA. Measuring the body composition of elderly subjects: a comparison of methods. Br f Nutr 1994: 72: 33-44.

9 Davies PSW, Lucas A. Prediction of body fatness in early infancy. Early Hum Dev 1989; 21 : 193-8.

10 Davies PSW, Preece MA. Body composition in children: methods of assessment. In: Tanner JM, Preece MA, eds. The physiology of growth. Cambridge: Cambridge University Press, 1989: 95-107.

11 Frerichs RR, Horsha DW, Berenson GS. Equations for estimating percentage body fat in children $10-14$ years old. Pediatr Res 1979; 13: 170-4.

12 Boileau RA, Wilmore JH, Loman TG, Slaughter $\mathrm{MH}$, Riner WF. Estimation of body density from skinfold thicknesses, circumferences, and skeletal widths in boys aged 8-11 years: comparison of two samples. Hum Biol 1981; 53: 575-92.

13 Janz KF, Nielsen DH, Cassady SL, Cook JS, Wu YT, Hansen JR. Cross-validation of the Slaughter skinfold Hansen JR. Cross-validation of the Slaughter skinfold Exerc 1993; 25: 1070-6.

14 Durnin JVGA, Womersley J. Body fat assessed from total body density and its estimation from skinfold thickness measurements on 481 men and women aged 16-72 years. Br F Nutr 1974; 32: 77-97.

15 Siri I. Body composition from fluid spaces and density: analysis of methods. In: Brozek J, Henschel A, eds. Techniques for measuring body composition. Washington, DC: National Academy of Sciences, 1961: 223-34

16 Durnin JVGA, Rahaman MM. The assessment of the amount of fat in the human body from measurements of skinfold thickness. Br $\mathcal{F}$ Nutr 1967; 21: 681-8.

17 Slaughter MH, Lohman TG, Boileau RA, et al. Skinfold equations for estimation of body fatness in children and youth. Hum Biol 1988; 60: 709-23.

18 Johnston JL, Leong MS, Checkland EG, Zuberbahler PC, Conger PR, Quinney HA. Body fat assessed from body density and estimated from skinfold thickness in normal 
children and children with cystic fibrosis. Am $\mathcal{f}$ Clin Nutr 1988; 48: $1362-6$.

19 Brook CGD. Determination of body composition of children from skinfold measurements. Arch Dis Child 1971; 46: 182-4.

20 Deurenberg P, Pieters JJL, Hautvast JGAJ. The assessment of the body fat percentage by skinfold thickness measureof the body fat percentage by skinfold thickness measure-
ments in childhood and young adolescence. Br 7 Nutr ments in childhood

21 Bland JM, Altman DG. Statistical methods for assessing agreement between two methods of clinical measurement. Lancet 1986; i: 307-10.
22 Spender QW, Cronk CE, Stallings VA. Fat distribution in children with cerebral palsy. Ann Hum Biol 1988; 15: 191-6.

23 Reilly J, Workman P. Is body composition an important variable in the pharmacokinetics of anticancer drugs? vancer Chemother Pharmacol 1994; 34: 3-13.

24 Parzikova J. Total body fat and skinfold thickness in children. Metabolism 1961; 10: 794-807.

25 Hammond J, Rona RJ, Chinn S. Estimation in community surveys of total body fat of children using bioelectrical impedance or skinfold thickness measurements. Eur f Clin Nutr 1994; 48: 164-71.

\section{The malaria tragedy: a pen torch in the darkness}

Eight jumbo jets crashed today. There were no survivors. Ninety per cent of the victims were children. The same happened yesterday, and the day before, and the day before that: in fact it has happened and will happen every day this year. That is the news. But it isn't jumbo jets crashing, if it were it would be the single fact foremost in the thoughts of almost every person in the developed world. The killer is malaria: 3000 deaths a day, nine out of every 10 a child. Malaria eradication has not happened, control is the aim, and clinical management the practical reality. A report from Kenya (Kevin Marsh and colleagues, New England fournal of Medicine 1995; 332: 1399-404) shows how children with falciparum malaria can be selected for more concentrated care.

Over a period of 2.5 years 7538 children were admitted to Kilifi District Hospital, 1866 with malaria. Eighteen of the children with malaria were moribund on arrival and died quickly and another four died later of causes other than malaria. The clinical features and outcome of the remaining 1844 children were analysed. Sixty four of the 1844 children (3.5\%) died. The important new finding is that respiratory distress is a main indicator of severe malaria and can be used together with impaired consciousness to choose children for more intense care. World Health Organisation (WHO) criteria for severe and complicated malaria consist of 10 major clinical and laboratory criteria, including pulmonary oedema, and five minor, supporting criteria. The work in Kenya showed that the WHO criteria identified $80 \%$ of the children who died but a simple clinical assessment based on two criteria, prostration (inability to sit unaided) and respiratory distress (alar flaring, chest recession, use of accessory muscles of respiration, or deep breathing) identified over $90 \%$. Six hundred and ninety eight children satisfied the WHO criteria and the mortality in them was $7 \cdot 3 \%$ compared with $8.9 \%$ for the 650 with prostration and/or respiratory distress.

The major cause of respiratory distress in these patients is thought to be metabolic acidosis and the main treatments blood transfusion and rehydration although severe anaemia was not a necessary concomitant of severe respiratory distress. The pathophysiology of respiratory distress in these children remains to be fully elucidated. 